\title{
Warning: Do Not Turtle Aquarium into Hot Water
}

\section{Dana $\mathrm{P}^{*}$}

Department Damghan, Damghan University School of science, Damghan, Iran

*Corresponding author: Dana P, Department Damghan University School of science, Damghan, Iran, Fax: 009892144710606, Tel: 00989120195880,E-mail: parisadana95@gmail.com

Citation: Dana P (2018) Warning: Do Not Turtle Aquarium into Hot Water. J Vet Sci Ani Husb 6(3): 303. doi: $10.15744 / 2348-9790.6 .303$

\section{Received Date: May 12, 2018 Accepted Date: August 21, 2018 Published Date: August 23, 2018}

\begin{abstract}
Aquatic turtles need the water proper temperature in order to live. If the water is too cold, they will get sick. But if the water is too warm, can also make them sick. Your turtle needs the water temperature suitable to be right in order to survive and be healthy. Like all reptiles, turtles are ectothermic or "cold-blooded" animals. That means they can't control their body temperatures. Their body temperatures are the same as the air and water around them within a few degrees. And like all animals, they need their body temperature to be in the correct range for their biological processes like respiration, digestion, metabolism, and resistance to disease to work properly. It is a report of a terrible accident that led to the deaths of 3 turtles in $90-93^{\circ} \mathrm{C}$ hot water. After two minutes the turtles dived into the water and plunged into a state of nervous shock. The blood were sampled from the turtles and then painted with the methylene blue furthermore turtle bodies were autopsied.
\end{abstract}

Keywords: Turtles; Water Temperature; Ectothermi; Autopsy

\section{Perspective}

The report is a real tragedy of the aquatic turtles that were stored at home. "The hot water and turtle death "I was very sad about the turtle death, and I decided to write this article as a warning for the people who take care of the turtles that don't happen again, Turtles (red), Ear is red and is transmitted outside its native range through pet trade and demand. They are the most common species of turtle.

\section{Introduction}

Red-eared slider turtles are entrained and transported outside their native range through the aquatic pet trade and through demand and ritualistic release. They are the most popular aquatic turtle species for home aquarists and have subsequently been transported globally. They are farmed in their native range and subsequently shipped within the United States as well as overseas to Europe and Asia. Red-eared sliders are one of several species commonly released during demand and ritualistic release. This primarily occurs in Asia and is well documented in Taiwan where sliders can be purchased specifically for this ceremony [1]. Red-eared slider turtle is the common name of the invasive species Trachemys scripta Elegans of the order Testudine, family Emydidae, They are named for the characteristic red postorbital stripes on either side of their heads and innate ability to slide off rocks and logs and into the water. The head, neck, legs, and tail of the slider are olive to brown in color and striped with cream to yellow colored ribbons. These markings on their limbs vary geographically and can come in the form of stripes, reticulations, ovals, etc. Toes are webbed and all bear foreclaws, males having elongated claws compared to females. The carapace is brown to olive with yellow markings that differ depending on the geographic location of the turtle. They have a yellow plastron made up of twelve scutes with distinct markings that range from blotches to intricate patterns. The plastron is slightly broader at the anterior than the posterior. Red-eared sliders have round heads with a protruding snout, a Y-shaped mark on their chin, and a black stripe that runs through their eyes [2]. Melanism is a common occurrence in older males of the species. It is the ontogenetic darkening of the skin, carapace, and scutes to brown and dark gray or green. The yellow markings on its limbs and head pale and become subdued, leaving the turtle uniform in color. The red stripe behind each eye fades and eventually turns gray. These turtles lack the characteristics by which the species in identified. There are two other distinct morphs of the red-eared slider; pastel and albino [3].These morphs are not common in nature, but the turtles are bred to specifically bear these unique colorings. As with melanism, the different morphology of the turtle makes it difficult to identify as a red-eared slider. Red-eared sliders are ectothermic, freshwater aquatic reptiles that spend their time foraging in densely vegetated ponds or basking on logs in the sun. They prefer quiet waters with soft, muddy bottoms, aquatic vegetation, and suitable sites for basking. Basking is important in thermoregulation of body temperature in red-eared 
sliders. Optimal body temperature is $28^{\circ} \mathrm{C}$ and is maintained by gaining energy from the sun [4]. Sliders will remain active year round depending on their geographic location. They Prefer temperatures ranging from 50 to $90 \mathrm{oF}$, but if the temperature drop below the critical level, the turtles will brumate. Otherwise they are active during the day and sleep during the night, either resting at the bottom or floating on the top of the water. Inside their native range the turtles fill an ecological niche as both a predator and a Prey item. They are hardy turtles, and thus outside their native range they fill the same Ecological niche with great adaptability [5].

\section{Materials and methods}

\section{Animals}

Three different turtle breeds: 1- Melanistic red-eared slider, 2- Pastel red eared slider, 3- Red-eared slider. The aquarium was kept under favorable conditions at $50{ }^{\circ} \mathrm{C}$ with proper water and food (Figure 1,2 and 3).

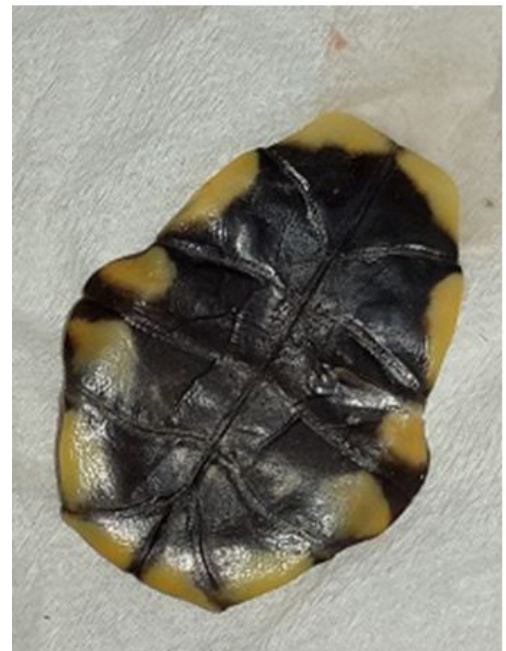

Figure 1: Plastron (Bottom shell) Turtles of Aquatic Turtles Melanistic red-eared slider

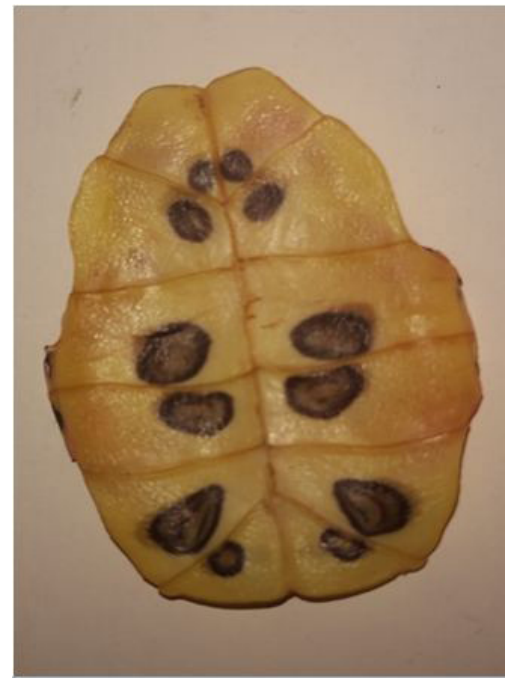

Figure 2: Plastron (Bottom shell) Turtles of Aquatic Turtles pastel red eared slider

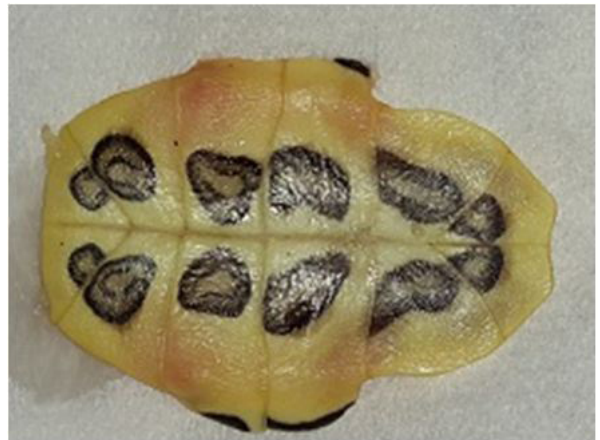

Figure 3: Plastron (Bottom shell) Turtles of Aquatic Turtles Red-eared slider 


\section{Critical Water Conditions}

Unfortunately, they were abandoned by the carelessness and neglect of tortoises in hot water. I briefly describe what I saw. I saw two tortoises in the water for two minutes. The turtles went to the bottom of the water and drowned their heads in a Loch. It was really unbelievable. I did not believe the tortoises were dead. The turtle Melanistic red-eared slider was left on the water but it was no longer moving, Tortoises were nervous and immediately died. I threw the tortoises again in cold water, but they were dead and this did not work. Immediately I threw the turtles into an autopsy and took blood samples from them and stained with methylene blue (Figure 6 and 7) and recorded everything I saw and decided to write this short article for people who keep the turtle, which is no longer a horrible event. It does not happen to them (Figure 4,5 and 11).

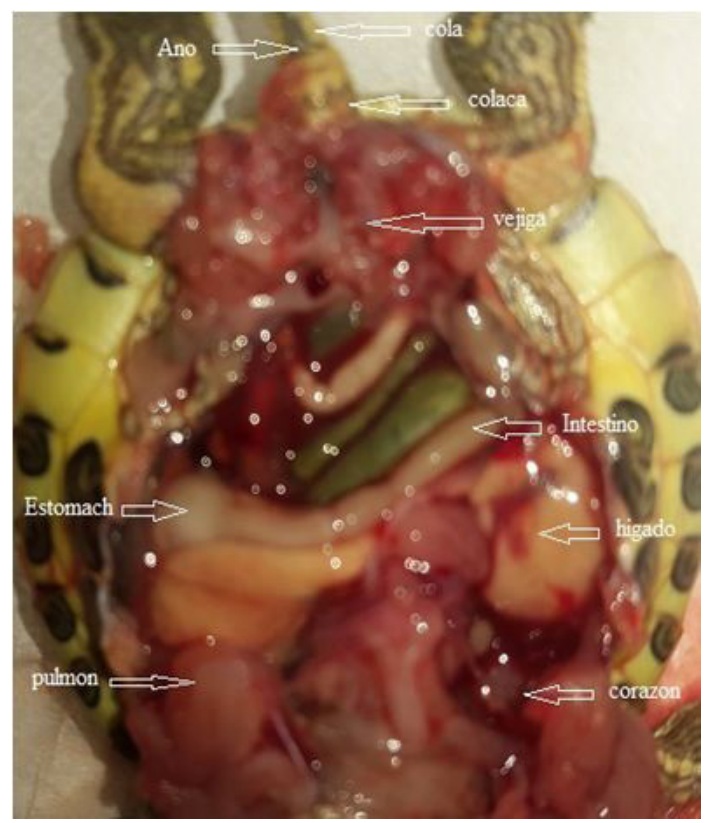

Figure 4: Different parts of the Abdomen Turtle

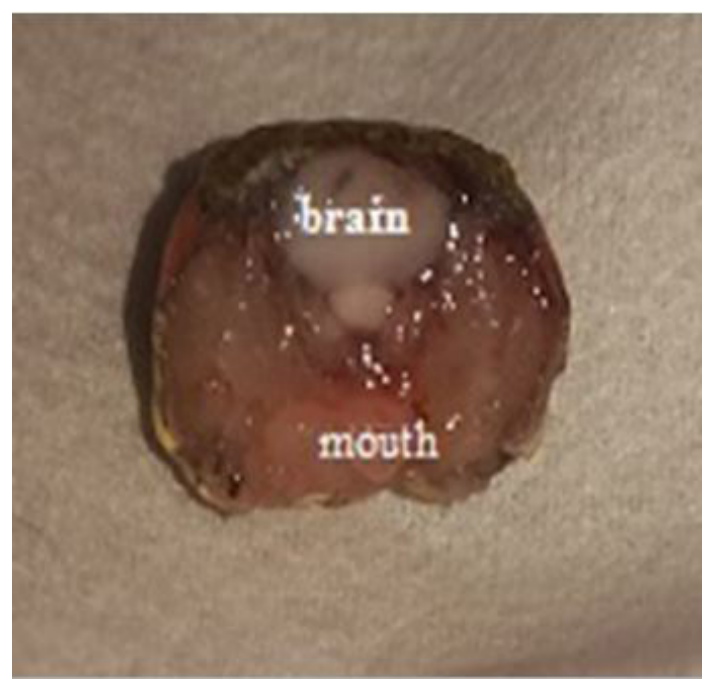

Figure 5: Crossing the Turtle Brain

\section{Red-eared slider}

The red-eared slider (Trachemys scripta elegans), also known as the red-eared terrapin, is a semiaquatic turtle belonging to the family Emydidae. It is a subspecies of the pond slider. It is the most popular pet turtle in the United States and is also popular as a pet in the rest of the world [6]. It has, therefore, become the most commonly traded turtle in the world [7]. It is native to the southern United States and northern Mexico, but has become established in other places because of pet releases, and has become an invasive species in many areas, where it out competes native species. The shell is divided into two sections: the upper or dorsal carapace, and the lower, ventral carapace or plastron [6]. The upper carapace consists of the vertebral scutes, which form the central, elevated portion; pleural scutes that are located around the vertebral scutes; and then the marginal scutes around the edge of the carapace. The rear marginal scutes are notched (Figure 8,9,10 and 12). The scutes are bony keratinous elements. The carapace is oval and flattened (especially in the male) and has a weak keel that is more pronounced in the young [8]. The color of the carapace changes 
depending on the age of the turtle. The carapace usually has a dark green background with light and dark, highly variable markings. In young or recently hatched turtles, it is leaf green and gets slightly darker as a turtle gets older, until it is a very dark green, and then turns a shade between brown and olive green. The plastron is always a light yellow with dark, paired, irregular markings in the center of most scutes. The plastron is highly variable in pattern. The head, legs, and tail are green with fine, irregular, yellow lines (Figure 1,2 and 3). The whole shell is covered in these stripes and markings that aid in camouflaging an individual. This is one of the most common methods of mortality in tortoise-burned tortoise. The tortoise has not been sustained due to severe burns due to high water temperatures and has lost its life after a while. The first reaction: Put the turtle in a container containing chlorine-free volumes of water and see the vet. If you do not have access to the vet, Take these steps before the veterinarian opens up: Follow the steps one by one: Immediately bring the turtle out of the water, and within a Place the plastic container with a suitable and dry place. Quickly measure the size of the floor She throws water on her to reduce her initial pain. She has burned and has been severely damaged very painfully and now she is full of lumbar punch all over her body, so be careful with Touch it. Put the betadine solution over the entire body and the turtle (bottom, side, and top) to prevent infection. A few seconds later, wash the turtle's head (staying on iodine on the eyes). Dangerous Let it goes for 30 minutes, wash it with lukewarm water and pour into the hands, neck (and not the eyes) areas between the hands and neck, legs, tail and all parts of puddle skin, and inside a Container p put a clean and dry steak. Spill on an eye drop on sterile eyes, his eyes are heavily damaged. After half an hour, thoroughly rinse the tortoise and then throw it in a plastic container of a size Fourth, the diameter of the turtle body, pour unpolluted lukewarm water, and pour a few capsules of cephalexin into the water and stir, then place the turtle in it. This will make the infection disappear or resolve before it reaches the veterinary.

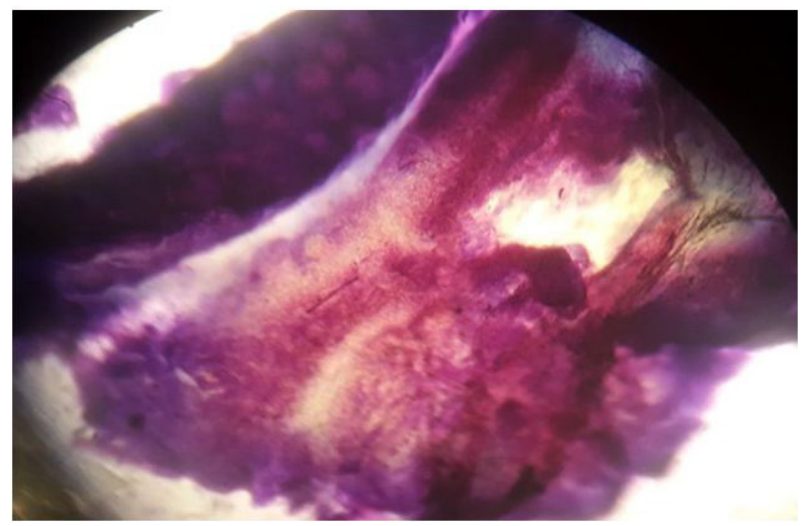

Figure 6: The microscopic image of the turtle ovaries

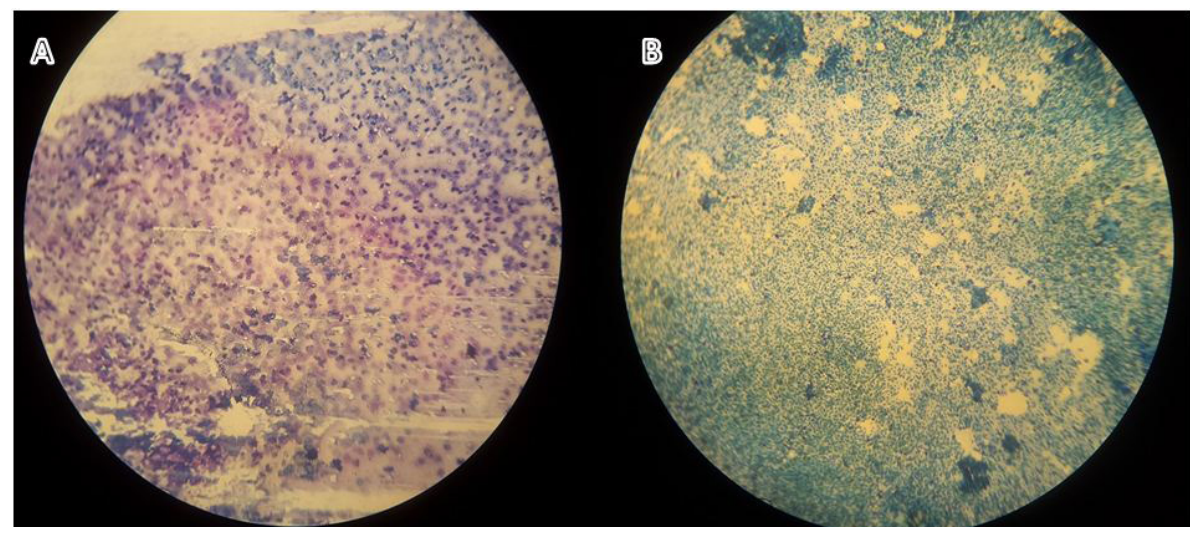

Figure 7: (A) Turtles Melanistic red-eared slider blood sample stained with methylene blue; (B) Turtles pastel red eared slider blood sample stained with methylene blue

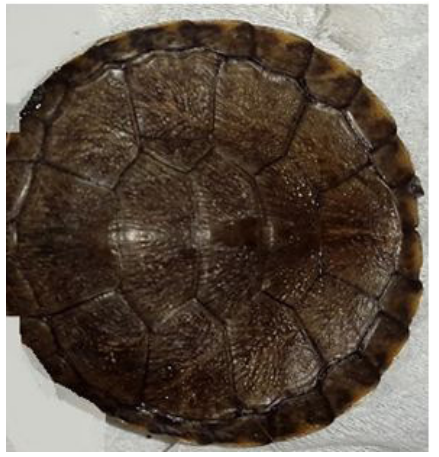

Figure 8: Carapace (top shell) Tortoise Melanistic red-eared slider 


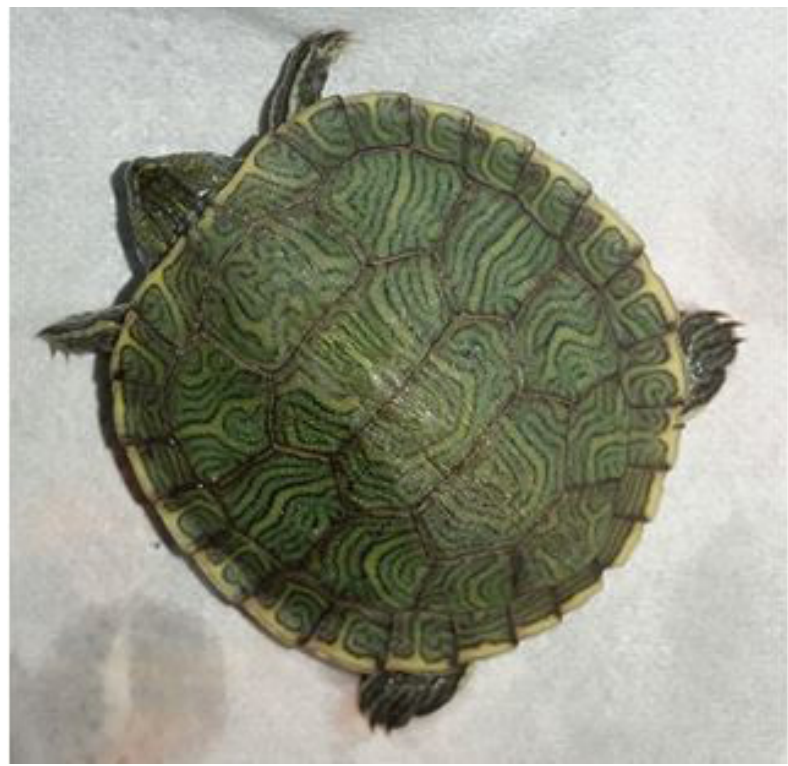

Figure 9: Carapace (top shell) Tortoise pastel red eared slider

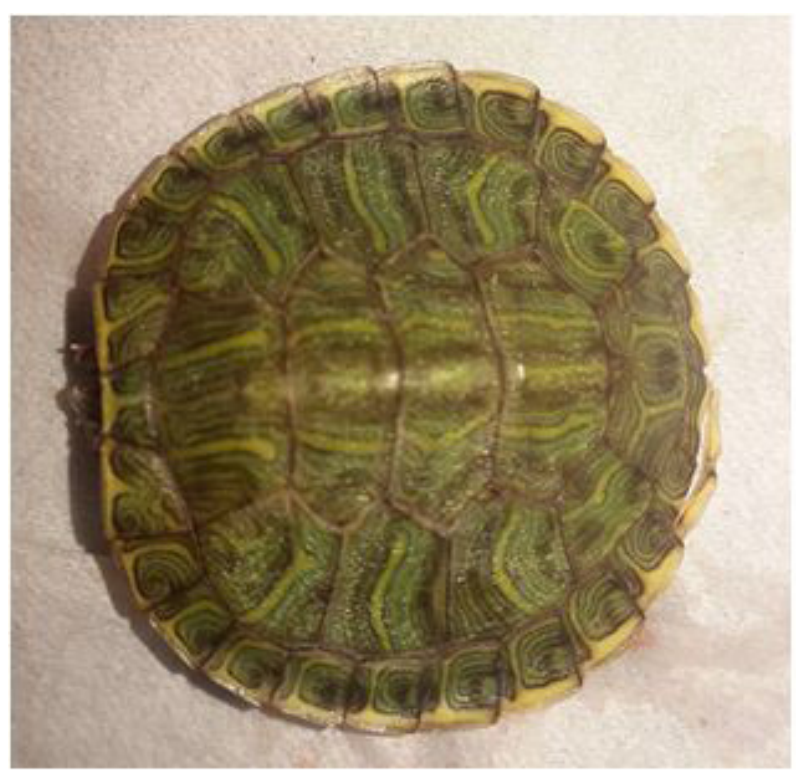

Figure 10: Carapace (top shell) Tortoise Red-eared slider

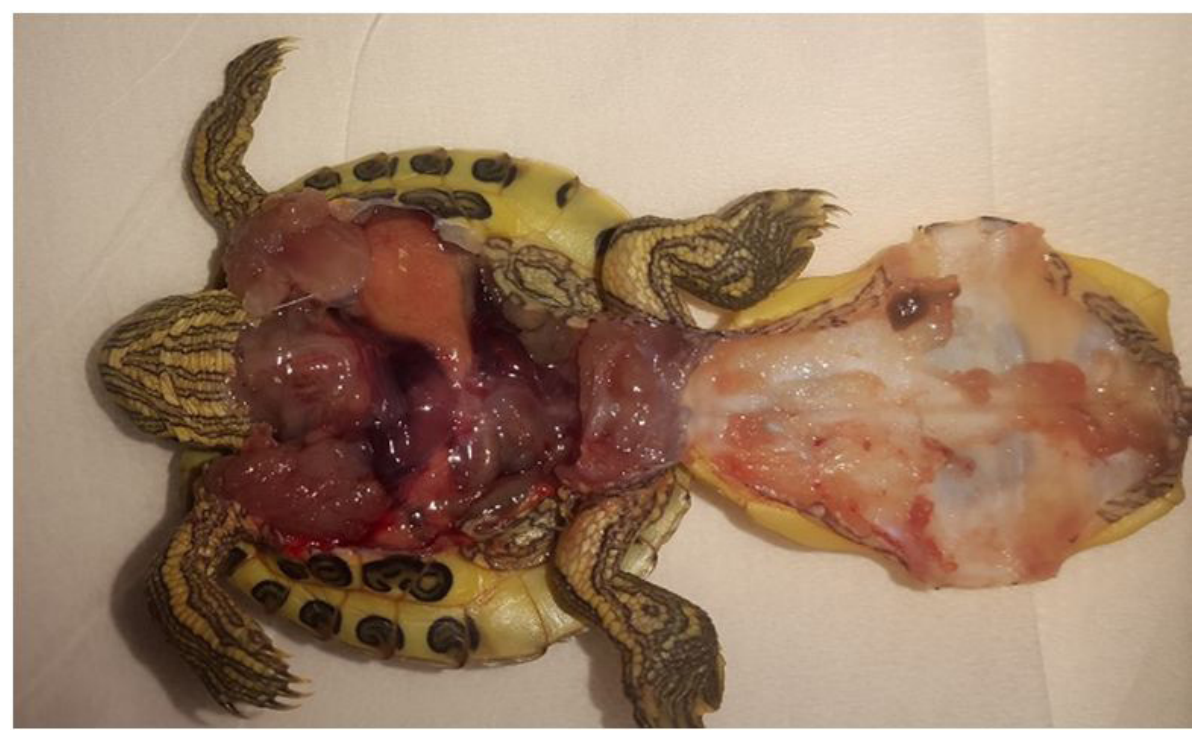

Figure 11: Anatomy of the turtle from the abdomen 


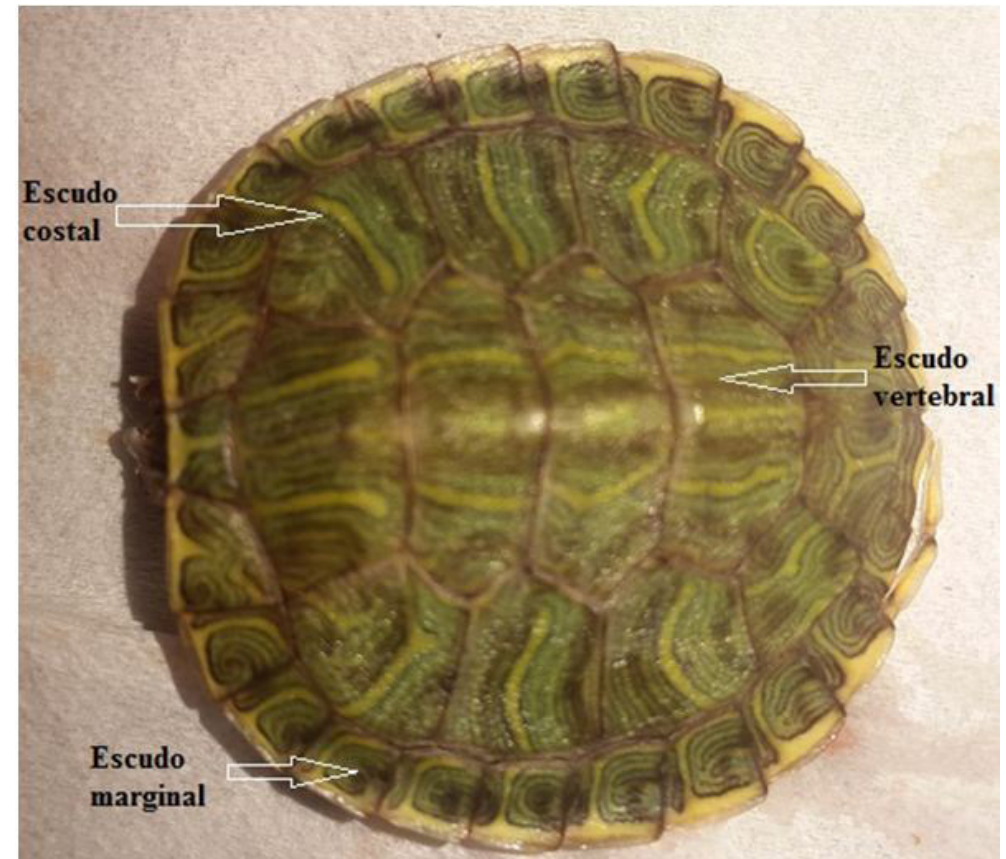

Figure 12: Different parts of the tortoise Carapace (top shell) Melanistic red-eared slider

\section{Ethics approval and consent to participate}

This study was approved by the Animal Research Ethics Board.

\section{References}

1. Hamilton-Smith E (2008) Review: Invasive Species in the Pacific Northwest by P.D. Boersma, S.H. Reichard \& A.N. Van Buren (Eds). Elect Green J 1.

2. McCleery RA, Moorman CE, Peterson MN (2014) Urban Wildlife conservation: Theory and Practice.

3. Ficetola GF, Padoa-Schioppa E, Monti A, Massa R, Bernardi FD, et al. (2004) The importance of aquatic and terrestrial habitat for the European pond turtle (Emys orbicularis): implications for conservation planning and management. Canadian Journal of Zoology 82: 1704-12.

4. Cadi A, Joly P (2004) Impact of the introduction of the red-eared slider (Trachemys scripta elegans) on survival rates of the European pond turtle (Emys orbicularis). Biodiversity \& Conservation 13: 2511-8.

5. Ramsay NF, Abigayle NP, O’Riordan RM, Chou LM (2007) The red-eared slider (Trachemys scripta elegans) in Asia: A review Chapter from book. Biological invaders in inland waters: Profiles, distribution, and threats 161-74.

6. Christensen-Dalsgaard J, Brandt C, Willis KL, Christensen CB, Ketten D, et al. (2012) Specialization for underwater hearing by the tympanic middle ear of the turtle, Trachemys scripta elegans. Proc Biol Sci 279: 2816-24.

7. Uwe F, Havaš P (2007) Checklist of Chelonians of the World. Vertebrate Zoology 57: 207-8.

8. Kikillus KH, Hare KM, Hartley S (2010) Minimizing false-negatives when predicting the potential distribution of an invasive species: a bioclimatic envelope for the red-eared slider at global and regional scales. Animal Conservation 13: 5-15.

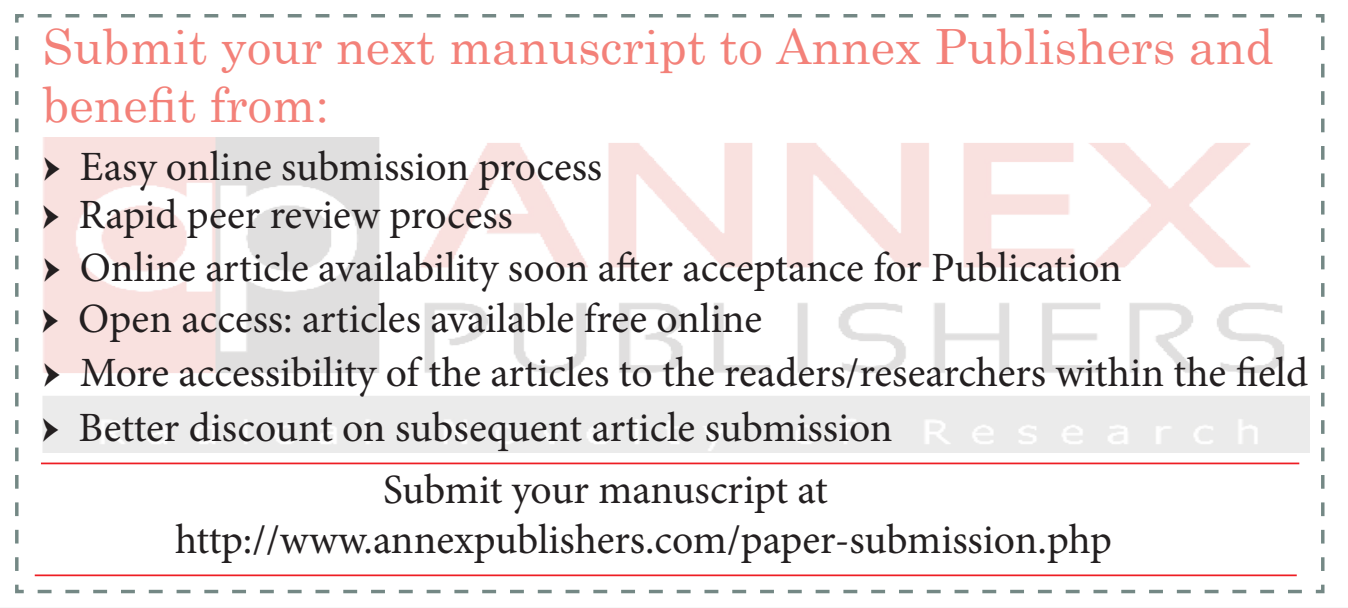

